Open Access

Original Article

\title{
Blood transfusion and high-order cesarean delivery; Report from a developing country
}

\author{
Shahida Abbas' ${ }^{1}$, Saba Mughal ${ }^{2}$, \\ Syeda Namayah Fatima Hussain ${ }^{3}$, Nazli Hossain ${ }^{4}$
}

\begin{abstract}
Background and Objective: Blood loss in cesarean deliveries has already been established in previous researches but a detailed insight into the correlates has not been done. This study examined whether the number of previous Cesarean sections is related to the need for blood transfusion, and risk factors for blood transfusion.

Methods: A retrospective review of 239 females who had undergone two or more Cesarean sections during the time period of 2015-2018 was done. Data collected included type of surgery (elective or emergency), age, parity, body mass index, estimated blood loss, operating time, level of surgeon, presence or absence of adhesions and number of transfused packed cell volume.

Results: About $9.2 \%$ patients received blood transfusion with an estimated average blood loss of $618.18 \mathrm{ml}$. Patients with adhesions from previous surgery, presence of placenta previa, multiparity were significantly likely to receive blood transfusion. It was found that women with more than two caesarian sections had high proportion of blood transfusion as compared to women who had two caesarian sections. However nonsignificant difference was observed in numbers of caesarean sections with blood transfusion.

Conclusion: Women undergoing Cesarean sections combined with any of the risk factors like increased body mass index, dense adhesions, uterine atony, hypertension and presence of placenta previa, were found to be at increased risk for a need for blood transfusions.
\end{abstract}

KEYWORDS: Blood transfusion, Cesarean section, Risk factors.

doi: https://doi.org/10.12669/pjms.35.6.539

How to cite this:

Abbas S, Mughal S, Hussain SNF, Hossain N. Blood transfusion and high-order cesarean delivery; Report from a developing country. Pak J Med Sci. 2019;35(6):1520-1525. doi: https://doi.org/10.12669/pjms.35.6.539

This is an Open Access article distributed under the terms of the Creative Commons Attribution License (http://creativecommons.org/licenses/by/3.0), which permits unrestricted use, distribution, and reproduction in any medium, provided the original work is properly cited.

1. Shahida Abbas, FCPS, MCPS.

Department of Obstetrics \& Gynecology,

Holy Family Hospital, Karachi, Pakistan.

2. Saba Mughal,

Department of Research,

3. Syeda Namayah Fatima Hussain, $4^{\text {th }}$ Year, MBBS.

Liaquat National Hospital \& Medical College, Karachi, Pakistan.

4. Nazli Hossain, FCPS, MBE.

Department of Obstetrics \& Gynecology,

2,4: DOW University of Health Sciences,

Karachi, Pakistan.

Correspondence:

Dr. Nazli Hossain,

Professor,

Department of Obstetrics \& Gynecology Unit-II, Dow University of Health Sciences,

Baba-e-Urdu Road, Karachi, Pakistan.

Email: nazli.hossain@duhs.edu.pk

* Received for Publication:

February 26, 2019

* Revision Received:

* Revision Accepted:
July 24, 2019

August 5, 2019

\section{INTRODUCTION}

Maternal mortality, maternal morbidity and maternal near miss have been linked to hemorrhage as their leading cause in developing nations. ${ }^{1}$ Globally the Cesarean section rate has increased, with the highest rates quoted for developed world. ${ }^{2}$ Pakistan has also seen a sharp rise in rate of Cesarean section. More than $80 \%$ of obstetric hemorrhages occur postpartum (PPH) and are responsible for $25 \%$ of maternal deaths each year. ${ }^{3}$ Cesarean section is also identified as an important cause of $\mathrm{PPH}$, carrying risk for major intraoperative blood loss. ${ }^{4}$ In obstetric practice, this makes cesarean section an important indicator for blood transfusion.

As the number of cesarean sections CS increase, the complexity and complications also increase 
simultaneously, and so does the need for blood transfusions. Other factors might also significantly contribute to blood loss during cesarean sections CS such as maternal age, body mass index (BMI), comorbidities like fibroid uterus, experience of surgeon, and duration of surgery. The risk of transfusion increases as the number of cesarean sections increases. Abdelazim I et al., found that risk for blood transfusion increased $4.7 \%$, in women having more than three Cesarean sections. ${ }^{4}$ However, preparing cross-matched blood in anticipation not only causes an economic burden but also scarcity of blood especially in a developing country like Pakistan. Studies have shown wastage and over ordering of blood products leading to a loss of not just money but also manpower and time of blood bank resources. Subsequently, this may lead to deprivation of blood to people in time of need since the country lacks a reliable donor base as well as a regulatory and governance setup. Also it adds to the emotional stress of the attendants who brought the patient. Due to paucity of data in our region, it becomes essential to evaluate the effectiveness of arranging blood, and blood products in cases of most common obstetrical surgical procedure of Cesarean section.

This study was aimed at identifying risk factors for blood transfusion in women undergoing repeat cesarean section. High order cesarean section was defined as women having 2 or more than two previous operative deliveries.

\section{METHODS}

This retrospective study was carried out at a secondary care center. The study period was from January 2015 to December 2018The hospital has a well established medical record system. The hospital receives patients mainly from the city. The number of annual deliveries of the hospital are 1500. The delivery room is managed by midwives and registrars. The operative delivery is carried out by the consultant, with at least a minimum of five years' experience. The hospital provides emergency services for twenty-four hours. Women having two or more cesarean sections were included in the study. Medical records were evaluated for age, parity, body mass index, duration of surgery, emergency or elective procedure, number of transfusions of blood and blood products, presence or absence of adhesions, and presence or absence of placenta previa. Also included were details of newborn including weight and APGAR score. Women were divided in two groups on the basis of whether they received blood transfusion or not. The study was approved by the Hospital's ethics committee. (Ethics Committee approval June 10, 2017).

Statistical analysis: The statistical analysis was carried out using Statistical Package for Social Sciences (SPSS) version 16.0. Frequency and percentage were used to describe categorical variables such as parity, number of previous Cesarean Sections (LSCS), type of surgery, hypertension, diabetes mellitus, adhesions, uterine atony and placenta previa. Range, mean and standard deviation (SD) were reported to describe continuous variables such as age, gestational age, Body Mass Index (BMI), estimated blood loss, operative time, hospital stay, birth weight, APGAR score at 1-minute and APGAR score at 5-minute. Normality of continuous variables was checked using Shapiro-Wilk test and Mann-Whitney U test was applied to check mean differences between groups of blood transfusion. Chi-square test was run to check association between categorical variables and blood transfusion. Univariate and multivariate binary logistic regression analyses were carried out, unadjusted and adjusted odds ratios (OR) with $95 \%$ confidence intervals $(\mathrm{CI})$ were reported for the blood transfusion by other independent factors. Multivariate model was adjusted for all those covariates whose p-values were found to be less than 0.25 in univariate logistic model. All test results having $\mathrm{p}$-values less than or equal to 0.05 level of significance were considered statistically significant.

\section{RESULTS}

A total of 239 pregnant females were included in this study who underwent two or more cesarean sections. Total number of Cesarean sections during the study period was 2482. Average age of females was 30.13 years with $\mathrm{SD} \pm 4.08$ years and ranged between 21 and 43 years whereas average BMI of females was 28.29 with SD \pm 5.71 and ranged between 18.1 and 59.5. Overall, 9.2\% $\quad(n=22)$ patients received a blood transfusion. Patients who underwent their third, fourth and fifth cesarean section were $76.6 \%(n=183), 20.9 \%(n=50)$ and $2.5 \%$, $(n=6)$, respectively. Majority of study participants $85.4 \%(n=204)$ had elective surgery. Mild, moderate and dense adhesions were observed in $154(64.4 \%)$, $18(7.5 \%)$, and 67 (28\%) women respectively. Patients who reported no/mild, moderate and dense adhesions were $64.4 \%(n=154), 7.5 \% \quad(n=18)$ and $28.0 \%(n=67)$, respectively (Table-I). 
Table-I: Baseline characteristics of the participants $(n=239)$.

\begin{tabular}{|c|c|c|}
\hline Characteristics & $n$ & $\%$ \\
\hline \multicolumn{3}{|c|}{ Blood transfusion } \\
\hline No & 217 & 90.8 \\
\hline Yes & 22 & 9.2 \\
\hline \multicolumn{3}{|l|}{ Parity } \\
\hline 2 & 158 & 66.1 \\
\hline 3 & 58 & 24.3 \\
\hline 4 & 23 & 9.6 \\
\hline \multicolumn{3}{|c|}{ No. of previous LSCS } \\
\hline 2 & 183 & 76.6 \\
\hline$>2$ & 56 & 23.4 \\
\hline \multicolumn{3}{|l|}{ Type of surgery } \\
\hline Elective & 204 & 85.4 \\
\hline Emergency & 35 & 14.6 \\
\hline \multicolumn{3}{|l|}{ Hypertension } \\
\hline No & 215 & 90.0 \\
\hline Yes & 24 & 10.0 \\
\hline \multicolumn{3}{|c|}{ Diabetes mellitus } \\
\hline No & 217 & 90.8 \\
\hline Yes & 22 & 9.2 \\
\hline \multicolumn{3}{|l|}{ Adhesions } \\
\hline No/mild & 154 & 64.4 \\
\hline Moderate & 18 & 7.5 \\
\hline Dense & 67 & 28.0 \\
\hline \multicolumn{3}{|l|}{ Uterine Atony } \\
\hline No & 232 & 97.1 \\
\hline Yes & 7 & 2.9 \\
\hline \multicolumn{3}{|c|}{ Placenta previa } \\
\hline No & 236 & 98.7 \\
\hline Yes & 3 & 1.3 \\
\hline
\end{tabular}

BMI: Body Mass Index,

LSCS: Lower Segment Cesarean Section.

The average estimated blood loss was $618.18 \mathrm{ml}$ with SD \pm 895.29 in transfused group and 248.43 $\mathrm{ml}$ with SD \pm 132.42 in non-transfused group. The average blood loss was significantly different between the groups (Mean difference=369.75). BMI (Mean difference=1.99) and hospital stay in days (Mean difference $=0.71$ ) also showed statistically significant mean differences between the groups of blood transfusion. Results showed that women with more than two caesarian sections had high proportion of blood transfusion as compared to women who had two caesarian sections. However non-significant difference observed in number of caesarean sections with blood transfusion. It was observed that those patients who had dense adhesions were transfused more compared to those who had no/mild adhesions. Whereas, it was found that adhesions were statistically significantly associated with blood transfusion $(=15.24)$. The presence of placenta previa $(=12.00)$, parity $(=8.70)$ and uterine atony $(=19.83)$ were also significantly associated with blood transfusion (Table-II).

The average birth weight of infants was slightly higher in transfused group as compared to not transfused group. However, birth weight, 1-minute and 5-minute Apgar scores did not show any statistically significant mean differences between the groups of blood transfusion (Table-III).

Univariate analyses revealed that patients with higher parity (parity $=4$ ) were more likely to receive a blood transfusion as compared to those who had lower parity (parity $=2$ ) and those patients who had dense adhesions were more likely to be transfused as compared to those who had no/ mild adhesions. It was also found that operative time, hospital stay, hypertension, uterine atony and placenta previa had statistically significant association with blood transfusion. After adjusting the multivariate logistic regression mode, it was again observed that hypertensive females were more likely to receive a blood transfusion than non-hypertensive females and females who had dense adhesions were more prone to be transfused as compared to those females who had no/mild adhesions. However, uterine atony and placenta previa remained consistent and showed significant association with higher risk for blood transfusion (Table-IV).

\section{DISCUSSION}

Cesarean section is associated with increased morbidity and mortality. Common complications include increased blood loss, sepsis, ileus, rupture of previous uterine scar and iatrogenic injuries to bladder and bowel. As a precautionary measure, the usual protocol in the hospital is to arrange minimum of one unit of packed red cell prior to surgery. The frequency of blood transfusion in this study was found to be $9.2 \%$. A study from neighboring country India quoted a higher rate of $12 \% .^{5}$

We found an increased risk for transfusion in women with increased body mass index, though it was not statistically significant. Paglia MJ et al. found an increased prevalence of $\mathrm{PPH}$ in cohort of more than 12,000 women, who had BMI $<30 .{ }^{6}$ Women with increased parity were also found to have more likelihood of receiving blood transfusion. This may be attributed to increased risk of uterine atony in this group of women. Uterine 
Table-II: Demographic characteristics of females undergoing cesarean sections by blood transfusion $(\mathrm{n}=239)$.

\begin{tabular}{|c|c|c|c|}
\hline Variables & $\begin{array}{c}\text { Transfused } \\
(n=22)\end{array}$ & $\begin{array}{l}\text { Not transfused } \\
\quad(n=217)\end{array}$ & $p$-value ${ }^{*}$ \\
\hline Age in years (Mean \pm SD) & $30.55 \pm 4.03$ & $30.09 \pm 4.10$ & 0.753 \\
\hline Gestational age in weeks (Mean \pm SD) & $36.59 \pm 0.85$ & $36.63 \pm 2.48$ & 0.272 \\
\hline BMI (Mean \pm SD) & $30.10 \pm 4.51$ & $28.11 \pm 5.80$ & 0.020 \\
\hline Estimated blood loss in $\mathrm{ml}($ Mean $\pm \mathrm{SD})$ & $618.18 \pm 895.29$ & $248.43 \pm 132.42$ & $<0.001$ \\
\hline Operative time in minutes (Mean $\pm \mathrm{SD}$ ) & $61.59 \pm 35.77$ & $46.49 \pm 7.42$ & 0.128 \\
\hline Hospital stay in days (Mean \pm SD) & $3.95 \pm 1.29$ & $3.24 \pm 0.62$ & 0.005 \\
\hline \multicolumn{4}{|l|}{ Parity, $n(\%)$} \\
\hline 2 & $12(7.6)$ & $146(92.4)$ & \multirow[t]{3}{*}{$0.013 \dagger$} \\
\hline 3 & $4(6.9)$ & $54(93.1)$ & \\
\hline 4 & $6(26.1)$ & $17(73.9)$ & \\
\hline \multicolumn{4}{|l|}{ No. of previous LSCS, $n(\%)$} \\
\hline 2 & $15(8.2)$ & $168(91.8)$ & \multirow[t]{2}{*}{$0.330 \dagger$} \\
\hline$>2$ & $7(12.5)$ & $49(87.5)$ & \\
\hline \multicolumn{4}{|l|}{ Type of surgery, $n(\%)$} \\
\hline Elective & $17(8.3)$ & 187 (91.7) & \multirow[t]{2}{*}{$0.337 \ddagger$} \\
\hline Emergency & $5(14.3)$ & $30(85.7)$ & \\
\hline \multicolumn{4}{|l|}{ Hypertension, $n(\%)$} \\
\hline No & $17(7.9)$ & $198(92.1)$ & \multirow[t]{2}{*}{$0.054 \ddagger$} \\
\hline Yes & $5(20.8)$ & $19(79.2)$ & \\
\hline \multicolumn{4}{|l|}{ Diabetes mellitus, $n(\%)$} \\
\hline No & $21(9.7)$ & $196(90.3)$ & \multirow[t]{2}{*}{$0.703 \ddagger$} \\
\hline Yes & $1(4.5)$ & $21(95.5)$ & \\
\hline \multicolumn{4}{|l|}{ Adhesions, $n(\%)$} \\
\hline No/mild & $7(4.5)$ & 147 (95.5) & \multirow[t]{3}{*}{$<0.001^{* *}$} \\
\hline Moderate & $1(5.6)$ & $17(94.4)$ & \\
\hline Dense & $14(20.9)$ & $53(79.1)$ & \\
\hline \multicolumn{4}{|l|}{ Uterine Atony, $n(\%)$} \\
\hline No & $18(7.8)$ & $214(92.2)$ & \multirow[t]{2}{*}{$0.002 \ddagger$} \\
\hline Yes & $4(57.1)$ & $3(42.9)$ & \\
\hline \multicolumn{4}{|l|}{ Placenta previa, $n(\%)$} \\
\hline No & $20(8.5)$ & $216(91.5)$ & \multirow[t]{2}{*}{$0.023 \ddagger$} \\
\hline Yes & $2(66.7)$ & $1(33.3)$ & \\
\hline
\end{tabular}

*p-value has been calculated using Mann-Whitney U test, tp-value has been calculated using Chi-square test, $\ddagger \mathrm{p}$-value has been calculated using Fisher's exact test.

atony leading to severe obstetric hemorrhage has also been observed in a large birth registry cohort from Norway. ${ }^{7}$ The risk for transfusion increases in women with placenta previa. This has also been seen by other investigators. ${ }^{8,9}$ Other risk factors which have been identified for increased risk of blood transfusion includes general anesthesia, emergency cesarean section, use of anticoagulants during antepartum period and eclampsia. Majority of $C D$ in our study were elective surgeries. We did observe an increased risk of transfusion in women with hypertension.

Table-III: Infant characteristics in females undergoing cesarean section $(n=239)$.

\begin{tabular}{lccc}
\hline Characteristics & $\begin{array}{c}\text { Transfused } \\
(n=22)\end{array}$ & $\begin{array}{c}\text { Not transfused } \\
(n=217)\end{array}$ & $p$-value§ \\
\hline Birth weight in kg (Mean \pm SD) & $2.84 \pm 0.36$ & $2.76 \pm 0.41$ & 0.449 \\
Apgar score at 1-min (Mean \pm SD) & $7.91 \pm 0.29$ & $7.79 \pm 0.67$ & 0.398 \\
Apgar score at 5-min (Mean \pm SD) & $8.86 \pm 0.46$ & $8.73 \pm 0.77$ & 0.512 \\
\hline
\end{tabular}

§p-value has been calculated using Mann-Whitney U test. 
Table-IV: Odds ratio for blood transfusion by important risk factors $(n=239)$.

\begin{tabular}{|c|c|c|c|c|}
\hline \multirow[t]{2}{*}{ Characteristics } & \multicolumn{4}{|c|}{ Blood transfusion } \\
\hline & ORa $(95 \% \mathrm{CI})$ & $p$ value & $\mathrm{ORb}(95 \% \mathrm{CI})$ & $p$-value \\
\hline Age in years & $1.03(0.92-1.14)$ & 0.616 & - & \\
\hline Gestational age in weeks & $0.99(0.84-1.18)$ & 0.946 & - & \\
\hline BMI & $1.05(0.99-1.13)$ & 0.123 & $1.04(0.93-1.15)$ & 0.532 \\
\hline Estimated blood loss in $\mathrm{ml}$ & $1.00(1.00-1.01)$ & $<0.001$ & $1.00(1.00-1.01)$ & 0.089 \\
\hline Operative time in minutes & $1.07(1.02-1.12)$ & 0.008 & $1.06(0.99-1.13)$ & 0.084 \\
\hline Hospital stay in days & $2.68(1.59-4.52)$ & $<0.001$ & $1.59(0.77-3.29)$ & 0.207 \\
\hline \multicolumn{5}{|l|}{ Parity } \\
\hline 2 & Ref & & Ref & \\
\hline 3 & $0.90(0.28-2.92)$ & 0.862 & $0.26(0.04-1.64)$ & 0.152 \\
\hline 4 & $4.29(1.43-12.92)$ & 0.009 & $0.71(0.16-3.18)$ & 0.653 \\
\hline \multicolumn{5}{|l|}{ No. of previous LSCS } \\
\hline 2 & Ref & & & \\
\hline$>2$ & $1.60(0.62-4.14)$ & 0.333 & - & \\
\hline \multicolumn{5}{|l|}{ Type of surgery } \\
\hline Elective & Ref & & & \\
\hline Emergency & $1.83(0.63-5.34)$ & 0.266 & - & \\
\hline \multicolumn{5}{|l|}{ Hypertension } \\
\hline No & Ref & & Ref & \\
\hline Yes & $3.06(1.02-9.23)$ & 0.046 & $6.31(1.45-27.53)$ & 0.014 \\
\hline \multicolumn{5}{|l|}{ Diabetes mellitus } \\
\hline No & Ref & & & \\
\hline Yes & $0.44(0.06-3.47)$ & 0.439 & - & \\
\hline \multicolumn{5}{|l|}{ Adhesions } \\
\hline No/mild & Ref & & Ref & \\
\hline Moderate & $1.24(0.14-10.65)$ & 0.848 & $6.45(0.48-86.38)$ & 0.159 \\
\hline Dense & $5.55(2.12-14.48)$ & $<0.001$ & $13.62(2.63-70.66)$ & 0.002 \\
\hline \multicolumn{5}{|l|}{ Uterine Atony } \\
\hline No & Ref & & Ref & \\
\hline Yes & $15.85(3.29-76.37)$ & 0.001 & $49.03(4.16-578.30)$ & 0.002 \\
\hline \multicolumn{5}{|l|}{ Placenta previa } \\
\hline No & Ref & & Ref & \\
\hline Yes & $21.60(1.87-248.75)$ & 0.014 & $77.25(1.72-3464.24)$ & 0.025 \\
\hline
\end{tabular}

ORa: Unadjusted odds ratio, ORb: Odds ratio adjusted for BMI, estimated blood loss, operative time, hospital stay, parity, hypertension, adhesions, uterine atony and placenta previa, CI: confidence interval.

The risk of transfusion was found to be increased in the presence of adhesions. It was more increased with dense adhesions, also resulting in an increase in the procedure duration. Both the factors significantly increased the risk for blood transfusion. Adhesions are common after pelvic surgery. It has been found that the risk increased from $46 \%$ in women with previous one CS, to $83 \%$ in women with previous four CS. ${ }^{10}$ Presence of adhesions after CS, depends upon a number of factors including technique, expertise of surgeon, infection after procedure, duration of procedure. Lyell DJ, found a decreased prevalence of adhesions in women who had closure of peritoneum at the time of CS. ${ }^{11}$
Peritoneal closure was protective against both mild (three fold) and dense adhesions (five fold). In our study, the CS were carried out by more than six different consultants, with no uniform policy on peritoneal closure, hence we can not comment upon the fact that whether peritoneal closure at the time of CS is associated with decreased risk of adhesions at the time of CD. Moreover there is still no consensus on suturing or not suturing visceral and parietal peritoneum, and the type of suture material which may reduce adhesions. ${ }^{12}$

We had only two patients who had placenta previa with repeat CS. It is generally accepted that women with placenta previa do have an increased 
risk of transfusion, more so in the presence of adherent placenta. The majority of women who received transfusion in the study had adhesions, uterine atony and hypertension in the study.

We had a sizeable number of women who underwent repeat CS. The rate of transfusion comes around $9.2 \%$. This appears higher than other reported studies. The study does contradict the old theory that women with previous cesarean scar require blood transfusion. The risk of transfusion has been found to be increased in women undergoing repeat $\mathrm{CD}$, after five Cesarean deliveries. ${ }^{13}$ The risk factors identified from our study include parity, BMI, uterine atony, hypertension and presence of placenta previa.

In a large cohort of more than 50,000 women investigators combined the antepartum and intrapartum risk factors for peripartum transfusion. ${ }^{14}$ Anemia, abruption, general anesthesia and abnormal placentation (OR 92, CI 57.4- 147.6) were identified as the risk factors in this combined model.

Though our data is limited, and is retrospective in nature, it does identify the main indications for blood transfusion in women undergoing high order CS. It also provides a guideline for the caregivers when to order blood arrangement in women undergoing repeat CS.

\section{Conflict of interest: None.}

Grant Support E Financial Disclosures: None.

\section{REFERENCES}

1. Say L, Chou D, Gemmill A, Tuncalp O, Moller AB, Daniels J, et al. Global causes of maternal death: a WHO systematic analysis. Lancet Glob Health. 2014;2(6):e323-e333. doi: 10.1016/S2214-109X(14)70227-X

2. Betran AP, Ye J, Moller AB, Zhang J, Gulmezoglu AM, Torloni MR. The Increasing Trend in Caesarean Section Rates: Global, Regional and National Estimates: 19902014. PLoS One. 2016;11(2):e0148343. doi: 10.1371/journal. pone. 0148343

3. McLintock C, James AH. Obstetric hemorrhage. J Thromb Haemost. 2011;9(8):1441-1451. doi: 10.1111/j.15387836.2011.04398.x

4. Abdelazim I, Alanwar A, Svetlana S, Sakiyeva K, Farghali M, Mohamed M, et al. Complications associated with higher order compared to lower order cesarean sections. J Matern Fetal Neonatal Med. 2018:1-161. doi: 10.1080/14767058.2018.1551352
5. Goundan A, Kalra JK, Raveendran A, Bagga R, Aggarwal N. Descriptive study of blood transfusion practices in women undergoing cesarean delivery. J Obstet Gynaecol Res. 2011;37(10):1277-1282. doi: 10.1111/j.1447-0756.2010.01511.x

6. Paglia MJ, Grotegut CA, Johnson LN, Thames B, James AH. Body mass index and severe postpartum hemorrhage. Gynecol Obstet Invest. 2012;73(1):70-74. doi: 10.1159/000329335

7. Al-Zirqi I, Vangen S, Forsen L, Stray-Pedersen B. Prevalence and risk factors of severe obstetric haemorrhage. BJOG. 2008;115(10):1265-1272. doi: 10.1111/j.14710528.2008.01859.x

8. Spiegelman J, Mourad M, Melka S, Gupta S, Lam-Rachlin J, Rebarber A, et al. Risk factors for blood transfusion in patients undergoing high-order Cesarean delivery. Transfusion. 2017;57(11):2752-2757. doi: 10.1111/trf.14274

9. Bao Y, Xu C, Qu X, Quan S, Dong Y, Ying H. Risk factors for transfusion in cesarean section deliveries at a tertiary hospital. Transfusion. 2016;56(8):2062-2068. doi: 10.1111/ trf.13671

10. Morales KJ, Gordon MC, Bates GW, Jr. Postcesarean delivery adhesions associated with delayed delivery of infant. Am J Obstet Gynecol. 2007;196(5):461.e1-e6. doi: 10.1016/j. ajog.2006.12.017

11. Lyell DJ, Caughey AB, Hu E, Daniels K. Peritoneal closure at primary cesarean delivery and adhesions. Obstet Gynecol. 2005;106(2):275-280. doi: 10.1097/01. AOG.0000171120.81732.4c

12. Bamigboye AA, Hofmeyr GJ. Closure versus non-closure of the peritoneum at caesarean section: short- and long-term outcomes. Cochrane Database Syst Rev. 2014(8):CD000163. doi: 10.1002/14651858.CD000163.pub2

13. Rouse DJ, MacPherson C, Landon M, Varner MW, Leveno KJ, Moawad $\mathrm{AH}$, et al. Blood transfusion and cesarean delivery. Obstet Gynecol. 2006;108(4):891-897. doi: 10.1097/01.AOG.0000236547.35234.8c

14. Ahmadzia HK, Phillips JM, James AH, Rice MM, Amdur RL. Predicting peripartum blood transfusion in women undergoing cesarean delivery: A risk prediction model. PLoS One. 2018;13(12):e0208417. doi: 10.1371/journal. pone. 0208417

\section{Authors' Contribution:}

SA and NH designed the study.

SNFH was responsible for data entry and initial write up.

SM conducted the statistical analysis.

NH Prepared the final version of manuscript and is responsible for integrity of research. 